\title{
Designing of nanosized bioflavonoids using biodegradable polymeric nanoparticles by Plackett burman method
}

\author{
${ }^{*}$ Nandhakumar Loganathan ${ }^{1}$ and Mohan Sellappan ${ }^{2}$ \\ ${ }^{1}$ Department of Pharmaceutical Sciences, Shri Jagdish Prasad Jhabharmal Tibrewala University, Jhunjhunu, Rajasthan, India \\ ${ }^{2}$ Head of Pharmacy, Karpagam College of Pharmacy, Coimbatore, Tamilnadu, India
}

\begin{abstract}
In this present study, dual loaded flavono nanoparticulate systems have been developed for oral delivery of Naringin and Hesperidin to enhance its antioxidant and antidiabetic activities. The fabrication of Dual Loaded Flavono Nanoparticles by suitable method was optimized by Plackett Burman method. Optimization of the formulation requires proper designing of the experiments. For this reason only in our current study, the placket burman method has been projected for the formulation of nanoparticles biodegradable polymers encompass bioflavonoid isolates for the antidiabetic activity. Ten critical parameters influencing the formulation has been selected and designed in Plackett Burman method of experimentation for 12 runs to assess independent variables influencing the result outcome. The results revealed that the 9th run shows the optimum particle size of $126.1 \mathrm{~nm}$ with zeta potential of $29.9 \mathrm{mV}$. Remarkably significant nanoparticles were obtained by exploiting the Plackett Burman method as designing tool.
\end{abstract}

Key Words: Naringin, Hesperidin, nanocarriers, optimization, design of experiment, Nanoprecipitation method.

\section{INTRODUCTION}

Fundamentally, utilization of factorial design for the optimization of a process allows testing of many factors concomitantly and prevents the use of an unwanted number of runs or trials, thus it prevents material wastage and time consumption. (Nahar et al. 2006; Fan et al., 2012). Statistical design of experiment, is a perfect methodology to conduct and execute plan of experiments to extract the maximum amount of information with limited number of inputs. The most critical factors selected for the formulation along with the proper selection of design of experiment input a tool proves to be superior. DOE identifies optimal formulation conditions for these NPs provide understanding of the underlying relationship. Most commonly applied screening designs is the Plackett-Burman design (PBD) that evaluates larges number of factors and identify critical one in a minimal number of trials (Radhika et al., 2010). The utilization of Plackett-Burman experimental design paves the way for the study of numerous factors in a systematic and logical way to select optimized runs. The important significance of Plackett-Burman design method is quicker screening obtained with minimum possible experimental runs (Moorthi et al., 2012)

By and large, number of run needed to probe the main effects are equal to $2 \mathrm{n}$ or multiple of 4 in Plackett-Burman designs instead of 2 as in the relation of full -factorial designing (Moorthi et al., 2013). PBD screening design with 12 experimental run was designed utilizing Expert Design ${ }^{\circledR}$ (Ver 9; Stat-Ease, Inc, United States of America).
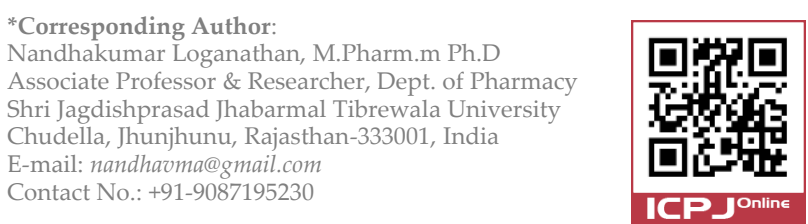

\section{MATERIALS AND METHODS}

Naringin and Hesperidin was purchased from Sigma Aldrich, Design of experiments used was obtained from Expert Design ${ }^{\circledR}$ (Ver 9; Statease, Inc, United States of America). By and large, number of run needed to scrutinize the main effects are equal to $2 \mathrm{n}$ or multiple of 4 in PlackettBurman designs instead of 2 as in the relation of full -factorial designing (Moorthi et al., 2013). PBD screening design with 12 experimental run was designed utilizing Expert Design ${ }^{\circledR}$ (Ver 9; Stat-Ease, Inc, USA).

The linear equation of this model is given as: $Y=b 0+b 1 X 1+b 2 \times 2+b 3 \times 3+b 4 X 4+b 5 \times 5+\cdots+b n X \mathrm{n}$

Where, $\mathrm{Y}$ is the responses, $\mathrm{b} 0$ is stable and $\mathrm{b} 1$....bn are coefficient of factor $\mathrm{X} 1, \mathrm{X} 2 \ldots \mathrm{Xn}$ (representing the consequence of every factor are within -1,+1). 24

Nevertheless, the process parameters which includes polymer concentration (A), surfactant concentration (B), aqueous phase concentration $(\mathrm{C})$ and organic phase concentration (D), duration of stirring (E), stirring speed $(\mathrm{F})$ addition of organic or aqueous phase $(\mathrm{G})$ and addition mode $(\mathrm{H})$. Consequently, PLB design was exploited to optimize the procedure parameter at lesser (-) and upper (+) level. The nanoparticle parameters such as Average particle size (R1), particle surface area (R2) and Surface area (R3) are considered as reliant variable. Twelve investigational runs exploiting 8 self-regulating progression variables at superior and inferior niche were generated exploiting Expert Designing ${ }^{\circledR}$ Version 9.

Fabrication of bioflavonoid nanoparticles

Polymer (Eudragit E 100) was dispersed in organic solvent, which was mixed into the aqueous phase encompass surfactant exploiting mechanical agitator. NPs were created instinctively and converting the aqueous to faintly milky with blue shade. However, stirring was sustained to support reduction in particle and also to evaporate surplus solvent existing in the NPs. Though, the constraints like polydispersity index, particle size and zeta potential of the nanoparticles based on the procedure parameters such as 
polymeric concentration, percentage of solvent, phase volumes, aqueous medium, surfactant concentration and magnetic agitating tenure. Therefore, PLB designing was exploited to standardize the progression parameters at lesser and superior niche. However, there are several methods available for the formation of NPs viz. desolvation method, dialysis method, ionic gelation method, nanoprecipitation method, direct solvent evaporation, salting out, supercritical fluid technology and spray drying (Ana et al., 2011; Xie et al., 2010) However, nanoprecipitation method is the most convenient \& cost effective way to generate polymeric NPs.

Particle sizing, polydispersity index (PDI) and zeta potential $(\mathrm{mV})$ analysis

The pure $(\mathrm{P})$, Naringin $(\mathrm{Nr})$, Hesperidin $(\mathrm{Ns})$ and Naringin-Hesperidin (Nr-Hs) polymeric nanoparticles were maintained at room temperature for 30 days, which were characterized for nanoparticles assessment (Yordonov et al., 2012). About $1 \mathrm{ml}$ of prepared plain and flavonoid loaded polymeric nanoparticles were diluted appropriately using distilled water, which was then taken individually in a zeta cell and measured nanoparticle assessment using Zetasizer (ZEN 3600, Malvern Instruments, Malvern, Worcestershire, UK). The experiments were executed in triplicate manner.

\section{Surface morphology analysis}

Prepared plain and flavonoid loaded polymeric nanoparticles were characterized for surface morphology using field emission scanning electron microscope (FESEM).

\section{Drug content, encapsulation efficiency \& drug loading estimation}

Drug content of prepared flavonoid loaded polymeric nanoparticles was evaluated by performing assay using the established HPLC methods for Naringin and Hesperidin (Tzu et al., 2008; Hector et al., 2012). Encapsulation effectiveness and loading of drug were assessed by measuring the free Naringin and Hesperidin in the nanoformulations.

Prepared plain and flavonoid loaded NPs were centrifuged exploiting refrigerated centrifuges for forty-five minutes for $19,000 \mathrm{RPM},-20^{\circ} \mathrm{C}$ and above portion was removed and stored individually for further analysis (Ana et al., 2012; Catarina et al., 2006).

About one $\mathrm{ml}$ of above was assorted with one $\mathrm{ml}$ of methanol, which then vortexed for 5 minutes and filtered through $0.22 \mu \mathrm{m}$ membrane. Estimated amount of unbound drug were denoted as $W_{\text {free. }}$ The experiments were carried in triplicates. Efficiency of encapsulation (EE) and drug loading (DL) were estimated as follows

$$
\begin{gathered}
E E(\%)=\frac{\text { Drug Content }\left(W_{\text {total }}\right)-\text { Drug in the supernatant }\left(W_{\text {free }}\right)}{\text { Drug Content }\left(W_{\text {total }}\right)} \times 100 \\
D L(\%)=\frac{\text { Drug Content }\left(W_{\text {total }}\right)-\text { Drug in the supernatant }\left(W_{\text {free }}\right)}{\text { Weight of the polymer used in the formulation }\left(W_{\text {polymer }}\right)} \\
\times 100
\end{gathered}
$$

Higher the particles in Brownian motion higher will be the stability of the nanoformulation. Since the likely charged particles, each other getting repelled against the weak vanders exists between particles due to dipole dipole interaction, because of gravitational force and hence, it prevents the agglomeration of particles altogether (Sergio et al. 2004). The polymer concentration, duration of processing, concentration of surfactant, organic phase volume has inverse relationship with that of zeta potential.

\section{RESULTS AND DISCUSSION}

Physiochemical evaluation of the nanoparticles

Plain, Naringin, Hesperidin, Naringin-Hesperidin Nanoparticles encompassed polymeric nanoparticulates were estimated for Particle surface, Polydispersity index and zeta potential $(\mathrm{mV})$. NPs prepared using stirring method were with an average particle size $<200 \mathrm{~nm}$, Polydispersity Index (i.e., $\mathrm{U}<0.7$ ) and Zeta potential $>20 \mathrm{mV}$.

\section{Surface morphology of the prepared nanoparticles}

Prepared Plain, Naringin, Hesperidin, and Naringin-Hesperidin loaded biopolymer nanoparticles were globular in character. Hence, all the nanoformulation encapsulated in the polymer milieu in circular shape for the basic function of nanoformulation, release of Naringin and bio-enhancers from the polymer matrix, transport of $\mathrm{Nr}$ and bio-enhancers in the body and internalization of Naringin and bio-enhancers by many folds than the free Naringin and bio-enhancers.

\section{Drug content, encapsulation efficiency \& drug loading es-} timation

The amount of $\mathrm{Nr}$ and Hs encapsulated in polymeric nanoparticles determines the effectiveness of prepared nanoformulations. Hence, drug content, encapsulation efficiency and drug loading estimated.

\section{Drug content, EE \& DL estimation}

Prepared, Plain, Naringin, Hesperidin, Naringin-Hesperidin nanoparticles were carefully kept at room temp for a month time to estimate any agglomeration and after-formulation deprivation. Prepared, Plain, Naringin, Hesperidin, Naringin-Hesperidin nanoparticles were characterized for particle size, polydispersity index and zeta potential.

After fabrication, prepared Plain, Naringin, Hesperidin, Naringin-Hesperidin nanoparticles matters were kept in room at a specified temperature for one month. However, there was no aggregation. Plain polymeric nanoparticles have shown an average particle size of $129.2 \mathrm{~nm}$ with PDI of 0.1841 and zeta potential of $27.3 \mathrm{mV}$. Naringin polymeric nanoparticles has shown an average particle size of $83.12 \mathrm{~nm}$ with PDI of 0.270 and zeta potential of $9.93 \mathrm{mV}$. Hesperidin polymeric nanoparticles have shown an average particle size of $102.3 \mathrm{~nm}$ with PDI of 0.361 and zeta potential of $13.80 \mathrm{mV}$. Naringin-Hesperidin polymeric nanoparticles have shown an average particle size of $91.20 \mathrm{~nm}$ with Polydispersity index of 0.306 and zeta potential of $15.3 \mathrm{mV}$. Off all the prepared nanoparticles the order of particle size is FE1 $<$ FE3 $<$ FE2 $<$ PL. Off all the prepared nanoparticles the order of Polydispersity index is $\mathrm{PL}<\mathrm{FE} 1<\mathrm{FE} 3<\mathrm{FE} 2$. Of all the prepared nanoparticles, the order of Zeta potential is PL>FE3>FE2>FE1.

Table 1: Optimization process parameters at lower and higher levels.

\begin{tabular}{cccc}
\hline \multirow{2}{*}{ Code } & \multirow{2}{*}{ Variables } & \multicolumn{2}{c}{ Levels } \\
& & Lower (-) & Higher (+) \\
A & Naringin & $50 \mathrm{mg}$ & $55 \mathrm{mg}$ \\
B & Hesperidin & $50 \mathrm{mg}$ & $55 \mathrm{mg}$ \\
C & Polymer concentration & $100 \mathrm{mg}$ & $250 \mathrm{mg}$ \\
D & Surfactant concentration & $15 \mathrm{mg}$ & $20 \mathrm{mg}$ \\
E & Aqueous Phase & $10 \mathrm{ml}$ & $20 \mathrm{ml}$ \\
F & Organic phase & $10 \mathrm{ml}$ & $15 \mathrm{ml}$ \\
G & Duration of stirring & $30 \mathrm{~min}$ & $60 \mathrm{~min}$ \\
H & Speed of stirring & $500 \mathrm{rpm}$ & $1000 \mathrm{rpm}$ \\
I & Addition type & Org to Aque- & Aqueous to \\
& & ous & org \\
J & Addition mode & All at once & By syringe \\
\hline
\end{tabular}


Table 2: Scheme of fabrication of flavonoid loaded nanoparticles by Plackett-Burman method.

\begin{tabular}{|c|c|c|c|c|c|c|c|c|c|c|}
\hline Trials & $\begin{array}{c}\text { Naringin } \\
\text { (mg) }\end{array}$ & $\begin{array}{l}\text { Hesperidin } \\
\text { (mg) }\end{array}$ & $\begin{array}{c}\text { Polymer } \\
\text { (mg) }\end{array}$ & $\begin{array}{l}\text { Surfactant } \\
(\mathrm{mg})\end{array}$ & $\begin{array}{l}\text { Aqueous } \\
\text { Phase (ml) }\end{array}$ & $\begin{array}{c}\text { Organic } \\
\text { Phase (ml) }\end{array}$ & $\begin{array}{c}\text { Stirring } \\
\text { rate (min) }\end{array}$ & $\begin{array}{c}\text { Stirring } \\
\text { Speed (rpm) }\end{array}$ & $\begin{array}{l}\text { Addition } \\
\text { mode }\end{array}$ & $\begin{array}{l}\text { Addition } \\
\text { Method }\end{array}$ \\
\hline 1 & 50 & 55 & 250 & 50 & 20 & 15 & 60 & 500 & $\mathrm{O}$ to $\mathrm{A}$ & All at once \\
\hline 2 & 50 & 50 & 250 & 50 & 20 & 15 & 30 & 1000 & A to $\mathrm{O}$ & By syringe \\
\hline 3 & 55 & 55 & 100 & 100 & 20 & 15 & 30 & 500 & $\mathrm{O}$ to $\mathrm{A}$ & By syringe \\
\hline 4 & 55 & 50 & 100 & 50 & 20 & 10 & 60 & 1000 & $\mathrm{O}$ to $\mathrm{A}$ & By syringe \\
\hline 5 & 50 & 50 & 100 & 100 & 15 & 15 & 60 & 500 & A to O & By syringe \\
\hline 6 & 50 & 55 & 100 & 100 & 20 & 10 & 60 & 1000 & A to $\mathrm{O}$ & All at once \\
\hline 7 & 50 & 55 & 250 & 100 & 15 & 10 & 30 & 1000 & $\mathrm{O}$ to $\mathrm{A}$ & By syringe \\
\hline 8 & 55 & 55 & 250 & 50 & 15 & 10 & 60 & 500 & A to O & By syringe \\
\hline 9 & 55 & 50 & 250 & 100 & 15 & 15 & 60 & 1000 & $\mathrm{O}$ to $\mathrm{A}$ & All at once \\
\hline 10 & 55 & 55 & 100 & 50 & 15 & 15 & 30 & 1000 & A to $\mathrm{O}$ & All at once \\
\hline 11 & 55 & 50 & 250 & 100 & 20 & 10 & 30 & 500 & A to $\mathrm{O}$ & All at once \\
\hline 12 & 50 & 50 & 100 & 50 & 15 & 10 & 30 & 500 & $\mathrm{O}$ to $\mathrm{A}$ & All at once \\
\hline
\end{tabular}

$\mathrm{O} \rightarrow \mathrm{A}=$ Organic phase to aqueous phase

$A-\rightarrow \mathrm{O}=$ Aqueous phase to organic phase

Table 3: Characterization of prepared nanoparticles.

\begin{tabular}{cccc}
\hline Runs & $\begin{array}{c}\text { Average Particle } \\
\text { Size (nm) }\end{array}$ & $\begin{array}{c}\text { Polydispersity In- } \\
\text { dex }\end{array}$ & $\begin{array}{c}\text { Zeta Potential } \\
\text { (mV) }\end{array}$ \\
\hline $\mathbf{1}$ & 735.3 & 0.599 & 0.200 \\
$\mathbf{2}$ & 174.9 & 0.091 & 21.9 \\
$\mathbf{3}$ & 290.0 & 0.270 & 13.9 \\
$\mathbf{4}$ & 883.0 & 0.741 & 1.30 \\
$\mathbf{5}$ & 1200.0 & 0.871 & 2.71 \\
$\mathbf{6}$ & 181.9 & 0.136 & 18.9 \\
$\mathbf{7}$ & 950.8 & 0.852 & 2.19 \\
$\mathbf{8}$ & 183.1 & 0.320 & 10.9 \\
$\mathbf{9}$ & 126.1 & 0.180 & 29.9 \\
$\mathbf{1 0}$ & 669.8 & 0.652 & 0.359 \\
$\mathbf{1 1}$ & 376.5 & 0.359 & -0.056 \\
$\mathbf{1 2}$ & 207.9 & 0.300 & 9.13 \\
\hline
\end{tabular}

Table 4: ANOVA table for Average particle size (Z)

\begin{tabular}{|c|c|c|c|}
\hline \multicolumn{2}{|c|}{ Parameters } & \multicolumn{2}{|c|}{ Numerical value } \\
\hline \multirow{2}{*}{\multicolumn{2}{|c|}{$\begin{array}{c}\text { P value } \\
\text { P value summary }\end{array}$}} & \multicolumn{2}{|c|}{$<0.0001$} \\
\hline & mary & \multicolumn{2}{|c|}{$* * *$} \\
\hline $\mathrm{P}<0$. & & \multicolumn{2}{|c|}{ Yes } \\
\hline Number of & roups & \multicolumn{2}{|c|}{12} \\
\hline F Val & & \multicolumn{2}{|c|}{13580} \\
\hline R Squa & & \multicolumn{2}{|c|}{0.9998} \\
\hline \multicolumn{4}{|c|}{ ANOVA Table } \\
\hline & Sum of Square & Difference & Mean of Square \\
\hline $\begin{array}{l}\text { Treatment } \\
\text { (between } \\
\text { columns) }\end{array}$ & 4616000 & 11 & 419600 \\
\hline $\begin{array}{l}\text { Residual } \\
\text { (within } \\
\text { columns) }\end{array}$ & 741.4 & 24 & 30.89 \\
\hline Total & 4617000 & 35 & - \\
\hline
\end{tabular}

Table 6: ANOVA table for Zeta potential (mV)

\begin{tabular}{|c|c|c|c|}
\hline \multicolumn{2}{|c|}{ Parameters } & \multicolumn{2}{|c|}{ Numerical value } \\
\hline \multicolumn{2}{|c|}{ P value } & \multicolumn{2}{|c|}{$<0.0001$} \\
\hline \multirow{2}{*}{\multicolumn{2}{|c|}{$P$ value summary }} & \multicolumn{2}{|r|}{$* * *$} \\
\hline & & \multicolumn{2}{|r|}{ Yes } \\
\hline \multicolumn{2}{|c|}{ Number of groups } & \multicolumn{2}{|r|}{12} \\
\hline \multirow{2}{*}{\multicolumn{2}{|c|}{$\begin{array}{l}\text { F Value } \\
\text { R Squared }\end{array}$}} & \multicolumn{2}{|r|}{10690} \\
\hline & & \multicolumn{2}{|r|}{0.9998} \\
\hline \multicolumn{4}{|c|}{ ANOVA Table } \\
\hline & Sum of Square & Difference & Mean of Square \\
\hline $\begin{array}{l}\text { Treatment } \\
\text { (between } \\
\text { columns) }\end{array}$ & 3306 & 11 & 300.5 \\
\hline $\begin{array}{l}\text { Residual } \\
\text { (within } \\
\text { columns) }\end{array}$ & 0.6746 & 24 & 0.02811 \\
\hline Total & 3307 & 35 & - \\
\hline
\end{tabular}

$(\mathrm{P}<0.05)$ are considered significant
Table 5: ANOVA table for Polydispersity index (PI)

\begin{tabular}{|c|c|c|c|}
\hline \multicolumn{2}{|c|}{ Parameters } & \multicolumn{2}{|c|}{ Numerical value } \\
\hline \multicolumn{2}{|c|}{$\begin{array}{c}\text { P value } \\
\text { P valummary }\end{array}$} & \multicolumn{2}{|c|}{$<0.0001$} \\
\hline \multicolumn{2}{|c|}{$P<0.05$} & \\
\hline Numb & of groups & \multirow{2}{*}{\multicolumn{2}{|c|}{$\begin{array}{c}12 \\
35850\end{array}$}} \\
\hline \multirow{2}{*}{\multicolumn{2}{|c|}{$\begin{array}{c}\text { F Value } \\
\text { R Squared }\end{array}$}} & & \\
\hline & & \multicolumn{2}{|r|}{0.9999} \\
\hline \multicolumn{4}{|c|}{ ANOVA Table } \\
\hline & Sum of Square & Difference & Mean of Square \\
\hline $\begin{array}{l}\text { Treatment } \\
\text { (between } \\
\text { columns) }\end{array}$ & 2.596 & 11 & 0.2360 \\
\hline $\begin{array}{l}\text { Residual } \\
\text { (within } \\
\text { columns) }\end{array}$ & 0.000158 & 24 & 0.000006583 \\
\hline Total & 2.596 & 35 & - \\
\hline
\end{tabular}


Table 7: Observed \& Predicted value of size, PDI and zeta potential

\begin{tabular}{|c|c|c|c|c|c|c|}
\hline \multirow{2}{*}{ Run } & \multicolumn{2}{|c|}{ Average Particle Size } & \multicolumn{2}{|c|}{ Polydispersity Index } & \multicolumn{2}{|c|}{ Zeta Potential } \\
\hline & $\mathbf{O}$ & $\mathbf{P}$ & $\mathrm{O}$ & $\mathbf{P}$ & $\mathbf{O}$ & $\mathbf{P}$ \\
\hline 1 & 735.3 & 732.2 & 0.599 & 0.599 & 0.200 & 0.198 \\
\hline 2 & 174.9 & 176.5 & 0.091 & 0.091 & 21.9 & 22.3 \\
\hline 3 & 290.0 & 289.3 & 0.270 & 0.270 & 13.9 & 13.9 \\
\hline 4 & 883.0 & 880.4 & 0.741 & 0.741 & 1.30 & 1.52 \\
\hline 5 & 1200.0 & 1215 & 0.871 & 0.871 & 2.71 & 2.23 \\
\hline 6 & 181.9 & 182.0 & 0.136 & 0.136 & 18.9 & 17.6 \\
\hline 7 & 950.8 & 952.3 & 0.852 & 0.852 & 2.19 & 2.34 \\
\hline 8 & 183.1 & 180.6 & 0.320 & 0.320 & 10.9 & 9.56 \\
\hline 9 & 126.1 & 123.5 & 0.180 & 0.180 & 29.9 & 30.7 \\
\hline 10 & 669.8 & 665.7 & 0.652 & 0.652 & 0.359 & 0.349 \\
\hline 11 & 376.5 & 374.2 & 0.359 & 0.359 & -0.056 & -0.072 \\
\hline 12 & 207.9 & 204.6 & 0.300 & 0.300 & 9.13 & 8.53 \\
\hline
\end{tabular}

O- Observed value, P- Predicted value.

Table 8: Average particles size, polydispersity index and zeta potential of prepared plain and flavono loaded polymeric nanoparticles

Formulation Average particle Polydispersity Zeta Potential

\begin{tabular}{|c|c|c|c|}
\hline Code & size $(\mathrm{nm})$ & Index & $(\mathrm{mV})$ \\
\hline PL & $129.20 \pm 0.176$ & $0.185 \pm 0.0003$ & $28.0 \pm 0.0577$ \\
\hline FE 1 & $83.12 \pm 0.0796$ & $0.270 \pm 0.001$ & $9.93 \pm 0.554$ \\
\hline FE2 & $102.30 \pm 1.506$ & $0.361 \pm 0.0026$ & $13.80 \pm 0.723$ \\
\hline FE3 & $91.20 \pm 1.537$ & $0.306 \pm 0.002$ & $15.03 \pm 0.441$ \\
\hline
\end{tabular}

Table 9: Optimized formulation for flavonoid loaded nanoparticles.

\begin{tabular}{ccc}
\hline $\begin{array}{c}\text { Sr. } \\
\text { No }\end{array}$ & Particulars & Parameters \\
\hline $\mathbf{1}$ & Trials No & 9 \\
$\mathbf{2}$ & Nr & $50 \mathrm{mg}$ \\
$\mathbf{3}$ & Hs & $50 \mathrm{mg}$ \\
$\mathbf{4}$ & Polymer Concentration & $250 \mathrm{mg}$ \\
$\mathbf{5}$ & Surfactant Concentration & $100 \mathrm{mg}$ \\
$\mathbf{6}$ & Aqueous Phase Concentration & $15 \mathrm{ml}$ \\
$\mathbf{7}$ & Organic Phase Concentration & $15 \mathrm{ml}$ \\
$\mathbf{8}$ & Duration of Stirring & $60 \mathrm{~min}$ \\
$\mathbf{9}$ & Speed of Stirring & $1000 \mathrm{rpm}$ \\
$\mathbf{1 0}$ & Addition of Organic or Aqueous & Organic to aqueous \\
& Phase & phase \\
$\mathbf{1 1}$ & Addition Mode & All at once \\
\hline
\end{tabular}




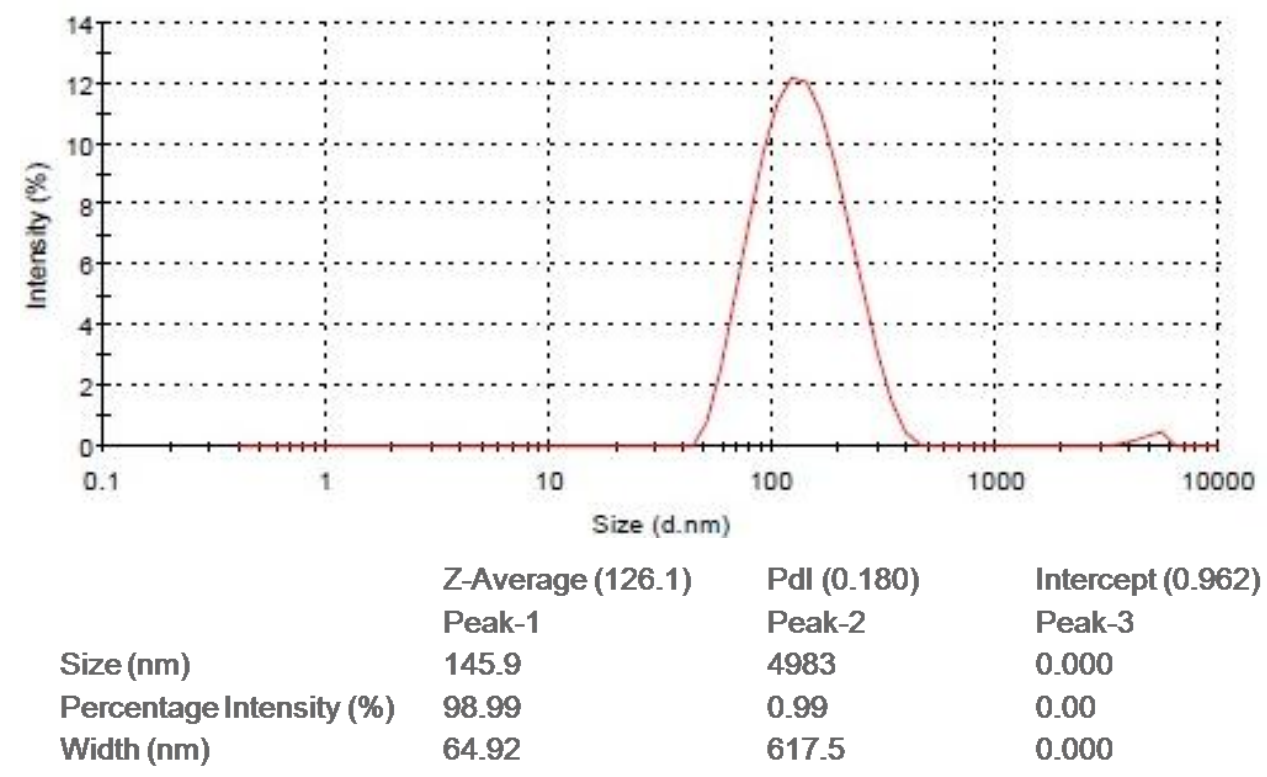

Figure 1: Particle size distribution of Run-9

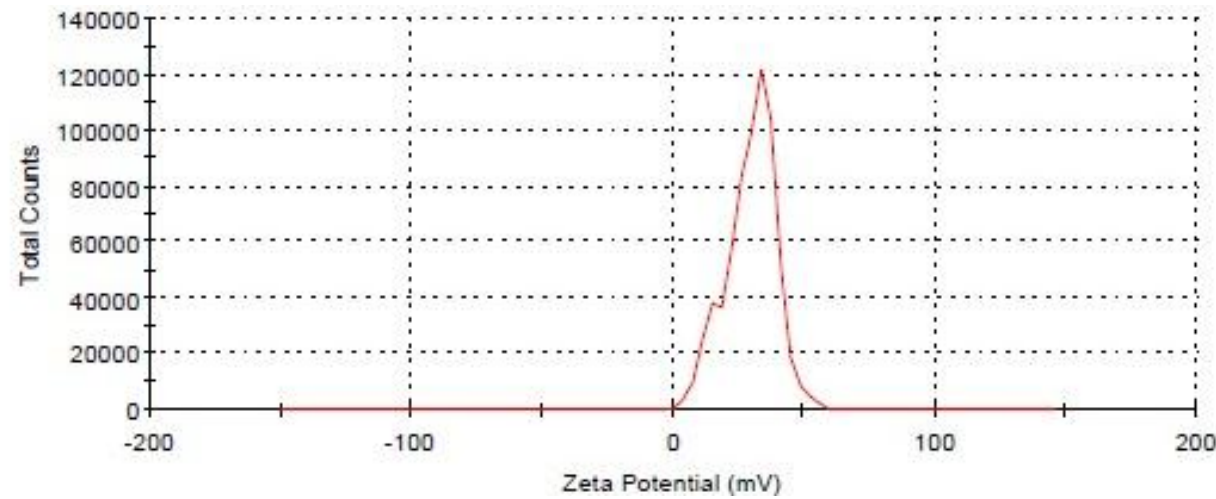

Zeta Potential (mV) (29.9) Zeta Deviation (9.5) Conductivity(0.0302)

Peak-1 Peak-2 Peak-3

$\begin{array}{llll}\text { Mean }(\mathrm{mV}) & 31.9 & 14.9 & 0.00\end{array}$

$\begin{array}{llll}\text { Percentage Area (\%) } & 84.1 & 15.9 & 0.0\end{array}$

$\begin{array}{llll}\text { Width }(\mathrm{mV}) & 7.36 & 3.99 & 0.00\end{array}$

Figure 2: Zetapotential (mV) distribution of Run-9 


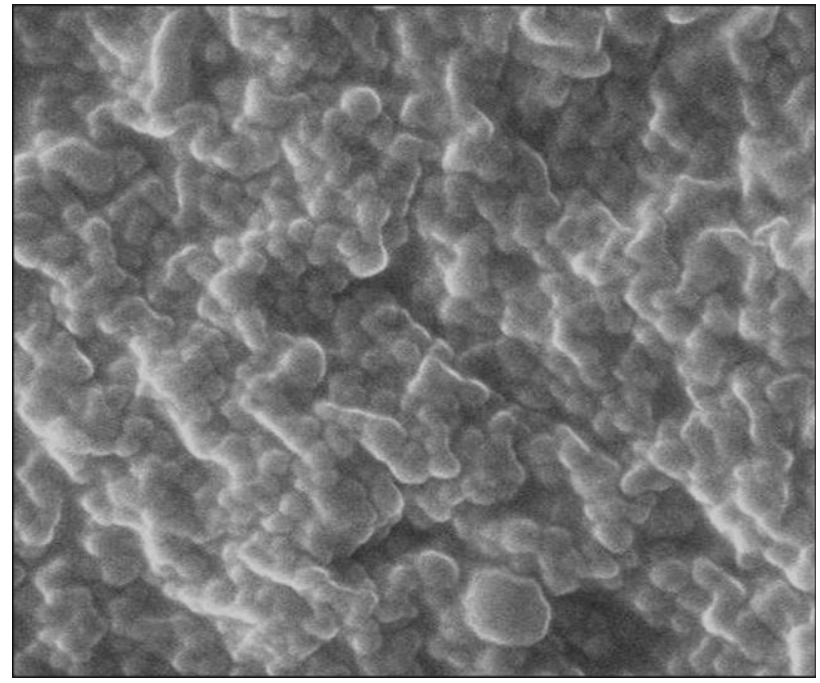

Figure 3: FESEM of Prepared Nanoparticles (Trial-9)

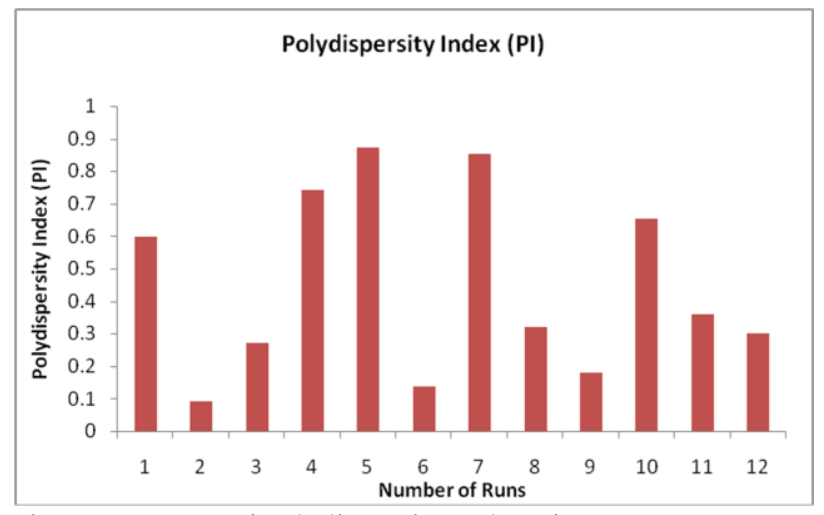

Figure 5: Pattern of Polydispersity Index of 12 runs

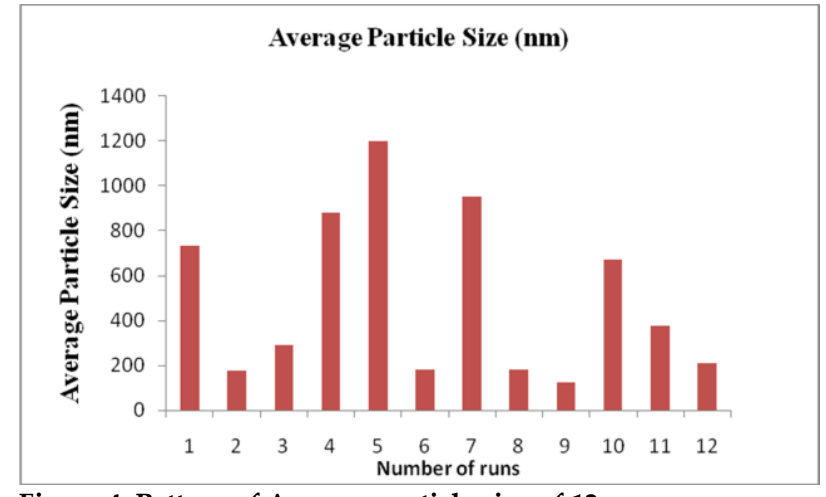

Figure 4: Pattern of Average particle size of 12 runs

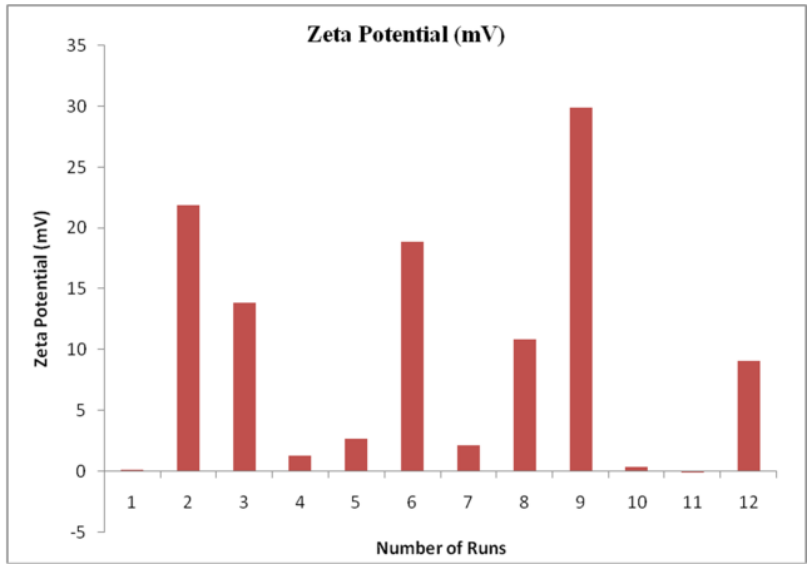

Figure 6: Pattern of Zeta Potential of 12 runs 


\section{CONCLUSION}

Both single loaded and dual loaded nanoparticle were successfully prepared by the nanoprecipitation method. The design of experiment tool Plackett burman method has significantly given the 12 runs for assessing the critical parameters affecting the experimental outcome. The critical parameters influencing the resulting nanoparticles formulation were identified by the designing tool. Based on the optimized trial out of 12 runs in placket burman design, the final formulation of Naringin and hesperidin single loaded, and Naringin-Hesperidin dual loaded nanoparticles were prepared. From the present investigation, it is concluded that the bioflavonoid nanoformulation fabrication using the placket burman as the identification of critical parameters, was more successful. It may significantly enhance and improve the antidiabetic and antioxidant activity for the treatment of diabetes mellitus.

\section{ACKNOWLEDGEMENT}

We wish to thank Shri Jagdishprasad Jhabarmal Tibrewala University and the Head, Department of Pharmacy, Karpagam College of Pharmacy, Tamilnadu for extending the cordial support for performing the research work.

\section{REFERENCES}

Ana, C.P., Michelle, F., Karen, C.D., Igor, P., Maria, F.D., (2011). Femandes, D.S., Preparation and characterization of polymeric nanoparticles loaded with luteolin, by using factorial design. International journal of drug delivery, 3(6), 683-698.

Ana, G.L., Jaime, L., Francisco, M.G., Miguel, A.V., Ana, L.A., Simon, B.H., (2012). Characterization and antiproliferative activity of Nobiletinloaded chitosan Nanoparticles. Journal of Nanomaterials, 1(2), 1-7.

Catarina, P.R., Ronald, J.N., Antonio, J.R., Francisco, V., (2006). Nanoencapsulation I. Methods for preparation of drug-loaded polymeric nanoparticles. Nanotechnology biology and medicine, 2(1), 8-21.

Fan, W., Yan, W., Xu, Z., Ni, H., (2012). Formation of monodisperse, low molecular weight chitosan nanoparticles by ionic gelation technique. Colloid Surface B, 90(1), 21-27. [DOI]

Hector, P., David, Q., Juang, D.F., Camila, M.M., Etelvino, H.B., Luis, A.G. (2012). Antioxidant effect of Quercetin and catechin encapsulated into PLGA nanoparticles. Journal of nanomaterials, 1(2), 1-12.

Moorthi, C., Kathiresan, K., (2013). Application of Plackett-Burman factorial design in the development of curcumin loaded Eudragit E 100 nanoparticles. Nano Biomed Eng, 5(1), 28-33. [DOI]

Moorthi, C., Kiran, K., Manavalan, R., Kathiresan, K., (2012). Preparation and characterization of curcumin-piperine dual drug loaded nanoparticles. Asian pacific journal of tropical medicine, 2(3), 841-848.

Nahar, M., Dutta, T., Murugesan, S., Asthana, A., Mishra, D., Rajkumar, V. Tare, M., Saraf, S., Jain, N.K., (2006). Functional polymeric nanoparticles: an efficient and promising tool for active delivery of bioactives. Crit Rev Ther Drug Carrier Syst, 23(4), 259-318. [DOI]

Radhika, R., Piramanayagam, S., (2010). Preparation and characterization of biopolymeric nanoparticles used in drug delivery. Indian Journal of Biochemistry and Biophysics, 47(1), 56-59.

Sergio, G.R., Eric, A., Hatem, F., Eric, D., (2004). Physiochemical parameters associated with nanoparticle formation in the salting-out, emulsification-diffusion and nanoprecipitation methods. Pharmaceutical research, 21(3), 1428-1439.

Tzu, H.W., Feng, L.Y., Liang, T.L., Tong, R.T., Chun, C.L., Thau, M.C., (2008). Preparation, physiochemical characterization and antioxidant effects of quercetin nanoparticles. International journal of pharmaceutics, 346(3), 160-168

Xie, H., Smith, J.W., (2010). Fabrication of PLGA nanoparticles with a fluidic nanoprecipitation system, J. Nanobiotechnology, 8(18), 1-7. [DOI]

Yordanov, G.G., Dushkin, C.D., (2012). Preparation of poly (butylcyanoacrylate) drug carriers by nanoprecipitation using a pre-synthesized polymer and different stabilizers. Colloid Polym Sci, 288(9), 1019-1026. [DOI] 